\title{
Verbalization and Learning in Handball
}

\author{
Zeineb Zerai \\ University of Manouba, Manouba, Tunisia \\ Email: zeraizizou@yahoo.fr
}

How to cite this paper: Zerai, Z. (2018) Verbalization and Learning in Handball. Advances in Physical Education, 8, 7-19. https://doi.org/10.4236/ape.2018.81002

Received: October 25, 2017

Accepted: January 26, 2018

Published: January 29, 2018

Copyright (C) 2018 by author and Scientific Research Publishing Inc. This work is licensed under the Creative Commons Attribution International License (CC BY 4.0).

http://creativecommons.org/licenses/by/4.0/

\begin{abstract}
The purpose of this study is to describe the effects of verbalization on the learning process. The methodology adopted consisted of recording the debate of ideas among Tunisian students after each learning situation during a complete Handballcycle. An analysis of content and discourse was carried out. Increasing the locational relevance of knowledge has played a key role in interactions, becoming a source of conflict/negotiation and even progress. Understanding, analyzing and interpreting the phenomena that occur during game play are essential to the development of effective action useful in the upcoming "rapport de forces".
\end{abstract}

\section{Keywords}

Verbalization, Debate of Ideas, Learning; Handball, Discourse Analysis, Tunisia

\section{Introduction}

Research in didactics of physical and sports activities raises the question of knowing how knowledge is elaborated (co-constructed) in the interaction between the subject and the context. This study is intended to analyze and understand how the dialogue between thought and action manifests itself (Alibali, Kita, \& Young, 2000).

One of the achievements of research in the teaching of team sports at school is that if the learning of a game cannot be conceived without an important practice, it also requires a distance with the immediacy of this practice. The challenge is to conceptualise action to construct operative invariants and rules of action (Vergnaud, Halbwachs, \& Rouchier, 1978; Gréhaigne, 1989, 1992). One does not learn while playing or repeating technical gestures.

It is necessary, in order to arrive at generalizations and the construction of meaning, to analyze afterwards what has happened. Our research is intended to 
produce knowledge and tools "for the intervention" (Bouthier, 2000). It seems that the richness of interactive modalities is a source of progress. Verbalisation is the transformation of thought into words. Language is an instrument for structuring and controlling thought. But, although intimately connected, language and thought are two autonomous functions. It is with learning that a link between thought and language begins to be established. Language is in fact the tool for transformation from an interpretative stage to a decision-making stage. The ambiguity of the relationship between language and action requires special precautions in the use of the "language tool". The minimum is to clarify the meanings of the words used. Learning thus becomes a matter of meaning and language. The learning/verbalization relationship deserves not only to be questioned, but also to be used in a didactic situation in order to facilitate learning in team sports.

The main concern for researchers was to allow students to co-construct their knowledge in order to solve problems encountered during game and develop an effective collective action project. It was thus necessary to describe the evolution of verbal exchanges in relation to the "rapport de forces" encountered by the student-players. Heuristic discussion implies not only a relational ethics (to have a concern for what the other thinks by temporarily adopting his/her point of view), but also an ethics of thought (to get to reason by negotiation). Its purpose is to seek an effective decision, within a community of practices that are being established.

Nachon (2004) showed two main functions of language interlocution in school basketball: a description/analysis function and a communication function. "They allow the exchange between individuals as well as the construction of projective verbalisations by putting forward the perceptions arising from the various commitments in action. It therefore rests on a principle of multi-functionality" (Nachon, 2004: p. 110). As far as the process of these functions is concerned, as soon as students answer a question or a comment from their teacher, a datum is put at the group's disposal. This way, the student-player who puts the proposal forward becomes a proposer who, for the most part, opens a path of reflection. This function is not trivial. Also, the datum can be set aside until there is, at a given moment, "a takeover by the collective entity". Thus, when a datum is put forward by a proposer, it may: 1) remain suspended, being neither false and/or unnecessary, nor true and/or important, but simply not being commented upon; 2) provide a path or a trail for the discourse to come, allowing the triggering of conversational sequences.

\section{Methodology}

In the context of this study, researchers focused on the learning/verbalization

${ }^{1}$ Many Anglophone colleagues have suggested that the French expression be used between quotation marks and that its meaning be explained. The "rapport de forces" refers to the "antagonist links existing between several players or groups of players confronted by virtue of certain rules of a game that determine a pattern of interaction" (Gréhaigne, Godbout, \& Bouthier, 1997: p. 516). 
relationship in their study of players' language interactions during learning situations, namely a confrontation in team sport (Chang, Wallian, \& Gréhaigne, 2008; Gréhaigne, 2009). The speakers, the players in this case, were invited to constantly exchange and negotiate based on what happened on the court during game play in order to agree and decide what they ought to do in order to win the match. In doing so, they co-constructed knowledge of action around the interpretations they made of game. Verbatim was studied in order to show the role of interactions in a context of knowledge construction with a focus on the cognitive aspect of oral communication as related to learning. Our work was based on the corpus of a thesis in didactics conducted earlier with Tunisian girls (Zerai, 2011).

The methodology used consisted of tape-recording, between game sequences and at the end of matches, the verbatim of a group of twenty $8^{\text {th }}$-grade Tunisian girls of Thala in a cycle of Handball. We chose this level because Tunisian girls begin to play team sports in high school. Students were divided into four subgroups to form the four teams that would compete against each other. The learning situations to be observed in a systematic way were inspired by those proposed by Nachon (2004). The 20 girls then went through a 12-hour work cycle. Each session consisted of different situations in the form of games in which the girls played five-to-five handball, including two goaltenders. The total duration of each match in the evaluation sessions was estimated to be 30 min (two 15-minute periods) (Figure 1).

For all girls, researchers noted, based on the students' verbatim, the following three dependent variables: co-construction with agreement, co-construction with the presence of argued disagreements, and finally acquiescent co-elaboration.

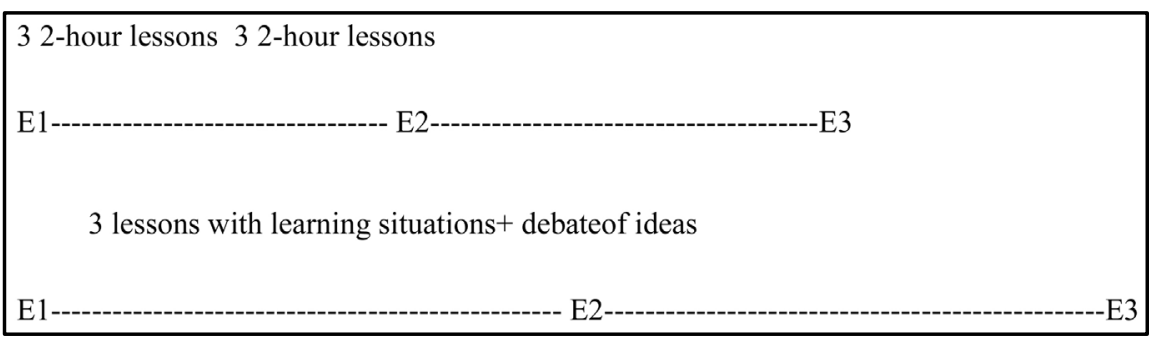

Figure 1. General schema of the Handball cycle and the collection of raw data.

\section{Results}

\subsection{Co-Construction with Agreement}

Conversational interactions show a very strong convergence both in the interactive dynamics adopted by girls and in the propositional content. The interlocutory analysis of some players is characteristic of an interactive mode without disagreement, the statements being linked (co-constructed) to develop essentially rules of action concerning the conduct of ball as well as the placement and displacement of the girls.

The interactive dynamic is of the order of co-construction. The sequence of statements is marked by "also" and "when" indicating that the act of language 
resumes and continues the preceding. We will present successively fragmented linguistic corpus to illustrate the dynamics of interactions between players.

\section{Excerpt from lesson 5/ team B}

Jihen: So let us apply the instructions. And above all determine the strategies of our opponent.

Marwa: When we have the ball, as soon as one of us passes the ball, we have to move fast to support our partner and disrupt the defender.

Nawel: Also, to arrive at each time to shoot, it is necessary that the person who does not have the ball moves towards the scoring zone.

Rabeb: Don't you find a difference between throwing the ball up and throwing the ball forward? We do not need high balls but long ones and not often.

Jihen: The recovery of the ball is not done in group-wise. Each has her place and her role; except in case of superiority, one can intervene. Otherwise we can not determine to who the next pass will be.

The dynamics of exchanges marks a constant alternation between subjects of speech; "We, we must, we...". This alternation illustrates the change of point of view and the transition from facts situated to more generic rules of action. There is, however, an attempt at guardian interaction on the part of a few.

\section{Excerpt from lesson 5/ team $B$}

Khawla: You must (MARWA) move immediately, decrease the dribbling, especially when there are defenders.

Jihen: You walk too much! (KHAWLA).

The initial knowledge at play is pass, dribbling, shooting and marking; Essentially the formal rules of the game. Other proposals take into account a decisional alternative but they do not have enough persuasive force to become a generalizable rule. The statements are marked by "it is necessary", demonstrating the search for effective rules of action in a perspective both generalizing and conforming. It should be noted that the obligation here is accompanied by arguments relating to the risk incurred in order to legitimize the proposal.

\section{Excerpt from lesson 5/ team $B$}

Marwa: We must disperse properly because otherwise we never get there.

\section{Excerpt from lesson 10/team $B$}

Rabeb: I think the most effective technique is to surprise the defender when she exchanges passes. It is necessary to deceive the opponents and to reverse game play. And as you have noticed, the displacement of the girls is a little long. 
Jihen: But also moving a lot disrupts the defenders and, at the same time, facilitates for us the passing of the ball and the shot. Don't you find that this is the case with our last goal?

Khawla: Maybe we got there but we have to be careful when we exchange the ball. The defenders are not stable and they also reason and remember that besides the defenders there is a goalkeeper. They follow our movements and try to determine who, when and how the shot will be done. What we must do then is to deceive them both (defenders and guardian).

Jihen: Anyway, you have to think when you want to score. We locate the partner, the opponent and the goal. Since the three factors depend on each other.

Focus is sometimes put on blending, placement, and speed of execution, which marks a slippage in the object of attention. The interactive dynamics is also characterized by joint and successive contributions to the development of a higher level response. The statements are rather declarative. They trace the action that has just taken place successfully. Other statements allow the construction of rules of action of more elaborate level with the taking into account of a decisional alternative according to the players. However, the language acts used are declarative and descriptive.

\section{Excerpt from lesson 5/ team $B$}

Nawel: In fact, as soon as the person throws the ball to the other person, we have to move; that is, the person who does not have the ball has to move. Afterwards, we pass the ball again and then we dribble it if necessary.

Khawla: As soon as we have the ball, we make only passes and when we reach the goal we make shots.

Rabeb: We make good passes but the ball goes away from the goal and off side. And to succeed, it would be necessary to make accurate shots and not in the air.

\section{Excerpt from lesson 10/ team $B$}

Nawel: We play against the best, you have to keep the group spirit, no individual decision. Even if we are better than they, we can lose and we don't want this to happen, OK? So to succeed, and if you want it of course, we must obey the rules of play and follow our strategy.

Khawla: I want to add something; we have to agree on an effective action. We must not wait for the defenders to advance a lot; on the other hand, we must move quickly and make fast and accurate passes. Even if we lose a little time it is not serious; the main thing is that we finally score our goal.

Rabeb: I think the most effective technique is to take the defender by surprise when she exchanges passes. It is necessary to deceive the opponents and reverse game play. And as you have noticed, the repositioning of the girls is a little long. 


\subsection{Co-Construction with Disagreement}

The analysis of other statements reveals interactive co-construction dynamics with more or less argumentative disagreements.

\section{Excerpt from lesson 5/ team $B$}

Rabeb: For advancing the ball, I propose a maximum and fast circulation of the ball and that we move over the whole court.

Khawla: Even with dribbling we scored a goal.

Rabeb: It's not often effective; you've seen how A4 was able to snatch the ball from you without any effort.

\section{Excerpt from lesson 10/ team $B$}

Nawel: After these matches, you noticed that our technique worked?

Rabeb: But it's not just about the application of technique, but also, and mainly because of our tactics of play. The opposing group also possesses technical qualities that cannot be ignored or neglected.

There appear combinations of exchange structures which show a logical intentionality in relation to the rules of action implemented on the court. The propositional content emphasizes technical and tactical knowledge. It would appear that the more capable girls are of developing sophisticated tactical skills, the more capable they are of arguing their point of view and of discussing with their partners to formulate rules of action. The analysis of the girls' verbal interactions in a situation of co-construction of rules of action in handball has a double interest. Results of the study show the importance of cooperation in handball learning situations and the valuable impact of some variety in players' competencies. Conversational analysis attempts to identify the cognitive processes used to co-construct rules of action reinvested in the construction of tactical skills. In order for there to be progress in the interaction between the players (who are likely to cooperate in the construction of tactical skills in collective sports), it appears that the interactive dynamics must be rich and varied in order to call for questioning.

\subsection{Accepting Co-Elaborations}

A final aspect of the analysis is that during the first session, the girls did not say anything about their matches.

After three learning sessions, it was noticed that the girls were beginning to express themselves, to describe what was happening, even before the periods reserved for the debate (they exchanged during the match). The statements aimed at collective agreement.

Excerpt from lesson 10/team $B$

Khawla: Our main goal is to win. We agree on this principle. 
Working as a group and keeping that cohesion as long as possible seems to be their first goal in order to win.

\section{Excerpt from lesson 10/team $B$}

Nawel: After playing for a while, we have noticed that our planning did not work well, that is, nothing has changed and the problem of conserving the ball and scoring goals still remains.

Jihen: Together we form a group and we are taking part into a collective game. And as the name suggests, it's played out in collaboration with all the members of our team.

Indeed, we have observed that non-co-development behaviors translate into ineffective responses in the perspective of new tactical skills. On the other hand, the resolution by negotiation of the socio-cognitive conflict with the confrontation of disagreements argued or not seems very interesting. However, the beneficial effects of the verbal interactions were observed without any conflict between the players under study. This highlights the fact that non-conflict interaction can produce disruption or destabilization among partners. At this point, the interactive dynamics leads to active cooperation between girls. Verbal interactions are characterized by a large number of speaking turns and a great richness in the interactive dynamics used. There are, at the same time, non-co-elaboration conducts, co-elaboration conducts, construction behaviours and some unsubstantiated disagreements. It seems that the richness of interactive modalities is a source of progress.

\subsection{Verbalization and Construction of Action Rules}

Action rules are elaborated, constructed and then stabilized through an awareness of the problems evoked during the verbalization between peers concerning game play actions in progress. "Each of us has to deal with an attacker, we must distribute the tasks among ourselves". It is therefore a back and forth process between situations on the court and verbalization. Indeed, by considering learning as a looping construct, awareness brings action and feedback into action. Players are then invited to debate in order to jointly develop an effective response to solve the problem posed by the situation. The verbal interactions on the action project, the result of the match, the relevance of the choices and the effectiveness of the actions after confrontation on the court with the other team lead to more conscious and sophisticated learning.

\section{Excerpt from lesson 5/ team $B$}

Rabeb: We have to break free from our opponent, to move so that we can make passes and normally, it must work in all cases.

Jihen: The recovery of the ball is not done group-wise. Everyone has her 
place and her role. Except in case of superiority, one can intervene; otherwise, one cannot anticipate to whom the next pass will go.

Marwa: When we defend, we mainly move toward the opponent and try to intercept the ball between passes; otherwise it's up to the goalkeepers to do better.

\subsection{Verbalization and Disagreement}

Disagreement between the players does not mean to do without others but rather not to depend on their intervention.

It is about having an identity within a group, a place and a role. As the apprenticeship progresses, the girls discard certain instructions because they no longer have any use but add others if they deem it necessary. They thus become capable of opening explicit negotiations between themselves in order to take new initiatives.

\section{Excerpt from lesson 5/ team $B$}

Nawel: I think what we have to do is avoid the defenders; for example, we dribble and throw the ball sideways. What do you think?

Jihen: I would rather, in fact, wait until the defender is in front of us to throw the ball.

\section{Excerpt from lesson 10/team $B$}

Jihen: But sometimes the defensive stuff did not work and we could not recover the ball. In fact, you have to stand in front of those who had the ball to catch it.

Khawla: Anyway, we have to think when we want to cover an opponent, we have to look at the [adverse]partner, the opponent and the goal to better determine the moment of shooting.

\subsection{Verbalization and Decision-Making}

From the analysis of the locutions, we observed that students, after playing a certain amount time with verbalization, have become capable of making decisions and appear to feel responsible for the results reached by their working group.

\section{Excerpt from lesson $10 /$ team $B$}

Rabeb: Which proves that concentration is essential in all tasks.

They have fun looking, they are curious; they know how to take initiatives to achieve their common goal. They ask for help or explanations and use all the means of information available to them. Discussions in the group improved the understanding of the game for some players. 


\section{Excerpt from lesson 10/team $B$}

Khawla: Also, you must have an effect of surprise. We have to deceive the opponent, we have to disrupt the defenders by changing passes and we must also change positions and we must move much faster so as not to give them an opportunity to organize themselves.

As a result, the girls were able to learn freely, the teacher imposing nothing on anyone: no information, no transmission of knowledge, no advice. Nevertheless, during the debate-of-ideas, the teacher may suggest learning situations that will provide students with a maximum of chances for progress. To make a decision is to face something new and unknown, but it is also sometimes necessary to acknowledge an error of judgment or to have to agree to give up something that was done or benefited until now. There are often worries at the heart of the decisions to be made: fear of losing control, fear of losing the respect of others.

\subsection{Verbalization and the Notion of Time}

Time is part of the notions considered as fundamental knowledge in team sports, along with the ball, the space and the conditions of game play. Players learn to locate, to orient themselves in time and to know it. This notion is structured and constructed through the time imposed by the teacher during learning situations and the time of debate-of-ideas that the girls appropriate in order to master the reasoning and thus develop their creativity.

\section{Excerpt from lesson 10/team $B$}

Rabeb: But we have to be careful, we do not have enough time to do what we want, we have to react quickly. Marwa: You're right, time is our second opponent that we have to take care of.

By relying on the principles of the debate of ideas players are led to base and structure their thought. Each girl becomes the driving force of her own learning. In order for learning to take place, a primary task is required, but it is crucial that there also be a project, namely a task that uses constructed knowledge or motor skills developed at the time of game play.

\subsection{The Construction of Shared Meaning}

There is agreement that in order to provide help in solving problems brought about by the game, decision-making should take the form of a heuristic construction of meaning (Landry, 1998; Vidal \& Lacroux, 2000) that makes it possible to discuss rather than decide. While decision-making should address the weaknesses of users, it is now a matter of helping them to identify what is their strong point: their ability to develop an alternative vision on a situation and to share it ("Determine our weak points."). In this perspective, decision-making 
would become interpretive-support processes making it possible to build collective action. Taking into account the modes of mental construction of the environment, recognizing the purpose of the subjects' behaviors and managing attention resources give rise to a certain awareness of the situation of play (" $B e$ careful about what is happening, during the match.").

To be aware of the situation is to be able to give the observed facts a coherent interpretation on the one hand and to anticipate the future states of these elements on the other hand. In all cases, the concept of awareness of the situation refers to a cognitive production directed towards the accomplishment of an activity in progress. This production therefore has, in essence, a limited lifespan with regards to the treatment of the tasks to be accomplished. Awareness of the situation depends on the extent to which the perception of a current environment reflects reality, globally and in details as well. It is the ability to identify, process and understand the critical elements of task-related information (Jones \& Endsley, 2000). The concept of awareness of the situation is strongly linked to the very theory of activity (Ochanine, 1978). This is based on the following premise: the processing of information of individuals is mediated by systems of representations directly oriented by the necessities of the tasks to be accomplished. When a player is confronted with a momentary configuration of play, she must quickly deal with multiple pieces of information at different levels and is constantly faced with the risk that her attentional skills be outdated. So, she must develop strategies to overcome these difficulties. The environment is the set of elements perceived by the subject; it will determine the framework of possible actions. However, in this environment, a configuration of play is not intended to be "decoded" as objectively as possible. It depends, on the one hand, on the opposition rapport and on the other hand on the characteristics of the subject (experiences, convictions, knowledge...). In other words, one tries to understand how the players establish the framework of possible actions in close relation to the situations they have to manage (" $A$ better appreciation of game play. Confrontation of ideas and elaboration of a collective solution."). With the distinction between cognitive and operative images in the strategies of comprehension and construction of meaning (Ochanine, 1978), we have a first element of response. Cognitive images are intended to be a distant, neutral and accurate representation of a situation, while operative images are established to finalize tasks. Beginners and more broadly individuals who are not responsible for the implementation of work tasks tend to establish cognitive, neutral and accurate images. Experts, who are oriented towards their objectives, rely on operative, partial, distorted images, but directly oriented towards action. This distinction between cognitive images and operative images is fundamental because it establishes an essential fact: subjects, who are responsible for an objective, guide the collection of information in order to form a representation to ensure that these objectives are achieved. Indeed, in the management of a complex activity, it is not enough to follow a procedure established to achieve the objectives. This 
usually consists in maintaining a system or process in an acceptable state by compromising between fuzzy and divergent criteria that cannot be put in order hierarchy-wise.

\section{Discussion}

During this experiment, we observed that the girls meet to exchange, share ideas, develop hypotheses, discuss and agree on game planning. During the debate, they try to gather the points of view of each and to draw a common representation of the situation. The players do not always agree; they can oppose or even confront each other, showing that productive verbalization allows the expression of divergent and even opposing ideas and points of view. When they discuss, their interest is to learn from the other, that is, to understand what others express but also to understand oneself in relation with others. From this point of view, the debate supports negotiations aimed at bringing together thoughts and narrowing the gap between the states of knowledge of each. Through the use of verbalization girls succeed in explaining their knowledge, in appropriating the knowledge of others, in bringing out new points of view and in developing a common orientation. They perceive learning with verbalization as an opportunity to grow and transform not only by integrating new knowledge but also by developing their collaborative abilities. It is a way to develop more responsibility and autonomy for themselves.

Following this study, we concluded that collaboration in the debate is essentially about interactions and dialogues, which gives importance to language interactions. It is in the verbal and ball exchanges that the team constructs itself; this moment makes it possible for it to exist and live through an adaptation to game play. The team becomes a genuine common space, a versatile resource center accessible to all. Moreover, in this space, the learner comes to deposit her productions to be shared with the group. These resources can be consulted by all, commented on using available data and discussed based on play sequences experienced. This kind of "interaction rituals" (Goffman, 1974) is the "meeting space" between students and between the teacher and his students (Baeza, 2001). During these exchanges, the girls try to reconcile their points of view in order to draw a unifying pattern. They agree on the purpose, the steps to be undertaken and the procedures to be implemented. Indeed, the development of knowledge is based on exploration work. This phase is characterized by negotiation, criticism, evaluation and validation of ideas to enrich the learner's learning model, a model with verbalization. They compare and negotiate points of view. They give and receive feedback and validate their new knowledge. What is most important for the members is to be together, to share their ideas, to share their achievements and to find support and assistance from the group. Discussion during the debate is used for mediation; it supports negotiation which aims at bringing the thoughts together and narrows the knowledge gap among players. The challenge of verbalization is to negotiate the putting together of the points of view of each 
individual and to come up with a collective schema that guides the teamwork. Answers progressively built by the linking of ideas lead to the formation of new concepts and give rise to another perception of the problem and its limits.

\section{Conclusion}

The use of verbal language by the players is the main source of their development. It is through language interactions with the social environment and in various forms that girls will be able to structure their thoughts. Also, language will give meaning and create links in a construction-transmission of knowledge by inviting them to explain learning situations as well as all the strategies used or usable. During the learning cycle, the players who had a discussion of ideas were able to point out their successes and weaknesses, to exchange ideas with their peers on strategies effective or not. They were also able to develop oral language skills not only in the field of communication but especially in the evocation language in addition to purely didactic and methodological skills.

Our research confirms the results of the literature concerning the dual pragmatic function of communication: an external communication function used to facilitate the understanding of tasks through verbal exchanges between the members of the group and a communication function "internal to the individual" allowing him to internalize the task. This linguistic communication is a practical, relational, reflexive act. There are therefore several operations in the same act of language: to evaluate, to comfort, to guide, to formulate a new question, to support and punctuate, to speak to a partner and to the whole group and take one's place in it. In a same didactic unit that lasts a few minutes, players must manage the tasks, the didactic contracts that underlie them and (re)evaluate the progress of the work (the usefulness of the strategy already planned) and the relations between them. It is therefore a question of putting the skills of analysis and intervention acquired in the learning sessions to the service of the tasks to be carried out so that they take place within the general framework of the game (collective decision-making, collective search of solutions, teamwork interactions, external communication).

\section{References}

Alibali, M. W., Kita, S., \& Young, A. J. (2000). Gesture and the Process of Speech Production: We Think, Therefore We Gesture. Language and Cognitive Processes, 15, 593-613. https://doi.org/10.1080/016909600750040571

Baeza, N. (2001). Morceaux choisis: Les interactions en EPS. Interagir avec ses élèves pour se construire en tant qu'enseignant [Selected Pieces: Interactions in PE. Interacting with One's Students in Order to Build Oneself as a Teacher]. Advanced Studies Diploma Thesis. Paris: Université Paris XI.

Bouthier, D. (2000). La coordination des décisions individuelles: Contribution de l'intelligence tactique [Coordination of Individual Decisions: Contribution of Tactical Intelligence]. Olympic Preparation Symposium-The Evolution of Tactical Thought. Noisy le Grand (France), 14-15 November. 
Chang, C. W., Wallian, N., \& Gréhaigne, J. F. (2008). The Tactical Knowledge Construction: Case Study on $5^{\text {th }}$ Grade Class in Basketball Games. TGFU Symposium, AIESEP World Congress, Sapporo (JP), 21-24 January.

Goffman, E. (1974). Les rites d'interaction [Interaction Rites]. Paris: Minuit.

Gréhaigne, J. F. (1989). Football de mouvement. Vers une approche systémique du jeu [Soccer in Movement. Towards a Systemic Approach of the Game]. Unpublished doctoral dissertation. Dijon: Université de Bourgogne.

Gréhaigne, J. F. (1992). L'organisation du jeu en football [The Organisation of Play in Soccer]. Paris: ACTIO.

Gréhaigne, J. F. (2009). Autour du temps. Apprentissages, espaces, projets dans les sports collectifs [Around Time. Learning, Spaces, Projects in Team Sports]. Besançon: PUFC.

Gréhaigne, J. F., Godbout, P., \& Bouthier, D. (1997). Performance Assessment in Team Sports. Journal of Teaching in Physical Education, 16, 500-516.

https://doi.org/10.1123/jtpe.16.4.500

Jones, D. G., \& Endsley, M. R. (2000). Examining the Validity of Real-Time Probes as a Metric of Situation Awareness. Proceedings of the 14th Triennial Congress of the International Ergonomics Association and the 44th Annual Meeting of the Human Factors and Ergonomics Society, Santa Monica, CA: Human Factors and Ergonomics Society. https://doi.org/10.1177/154193120004400175

Landry, M. (1998). L'aide à la construction de sensdansl'organisation [Help in Building Meaning in the Organization]. Système d'Information et Management, 3, 5-39.

Nachon, M. (2004). Interactions en éducation physique et sportive: Le cas du Basket-ball. Approche des compétences sémio-langagières et construction de savoirs [Interactions in Physical Education and Sport: The Case of Basketball. Approach to Semi-Angular Skills and Knowledge Building]. Thesis (unpublished) in Language Sciences. Besançon: University of Franche-Comté.

Ochanine, D. (1978). Le rôle des images opératives dans la régulation des activités de travail [The Role of Operative Images in the Regulation of Work Activities]. Psychologie et Éducation, 2, 63-72.

Vergnaud, G., Halbwachs, F., \& Rouchier, A. (1978). Structure de la matière enseignée, histoire des sciences et développement conceptuel chez l'enfant [Structure of Subject Matter, History of Science and Conceptual Development in the Child]. Revue Française de Pédagogie, 45, 7-18.

Vidal, P., \& Lacroux, F. (2000). L'évolution des systèmes d'aide à la décision: Du choix en décision structurée à l'intermédiation en situation complexe [Evolution of Decision Help Systems: From the Choice in Structured Decision to Intermediation in Complex Situations]. Système d'Information et Management, 5, 51-70.

Zerai, Z. (2011). Origine culturelle et apprentissage des sports collectifs chez les jeunes filles. Étude comparative d'élèvestunisiennesetfrançaises [Cultural Origin and Learning of Team Sports among Young Girls. Comparative study of Tunisian and French students]. Thesis in Physical and Sports Activities Didactics (unpublished). Besançon: University of Franche-Comté. 